\title{
npSCOPE: A New Multimodal Instrument for In Situ Correlative Analysis of Nanoparticles
}

\section{Journal Article}

\section{Author(s):}

De Castro, Olivier; Biesemeier, Antje; Serralta, Eduardo; Bouton, Olivier; Barrahma, Rachid; Hoang, Quang H.; Cambier, Sebastien; Taubitz, Tatjana; Klingner, Nico; Hlawacek, Gregor; Pinto, Serge Duarte; Gnauck, Peter; Lucas, Falk; Bebeacua, Cecilia; Wirtz, Tom

\section{Publication date:}

2021-11-02

Permanent link:

https://doi.org/10.3929/ethz-b-000516196

\section{Rights / license:}

Creative Commons Attribution 4.0 International

Originally published in:

Analytical Chemistry 93(43), https://doi.org/10.1021/acs.analchem.1c02337

\section{Funding acknowledgement:}

720964 - The nanoparticle Scope: a new integrated instrument for accurate and reproducible physico-chemical characterisation of nanoparticles (npSCOPE) (SBFI) 


\title{
npSCOPE: A New Multimodal Instrument for In Situ Correlative Analysis of Nanoparticles
}

\author{
Olivier De Castro,* Antje Biesemeier, Eduardo Serralta, Olivier Bouton, Rachid Barrahma, \\ Quang H. Hoang, Sebastien Cambier, Tatjana Taubitz, Nico Klingner, Gregor Hlawacek, \\ Serge Duarte Pinto, Peter Gnauck, Falk Lucas, Cecilia Bebeacua, and Tom Wirtz
}

Cite This: Anal. Chem. 2021, 93, 14417-14424

Read Online

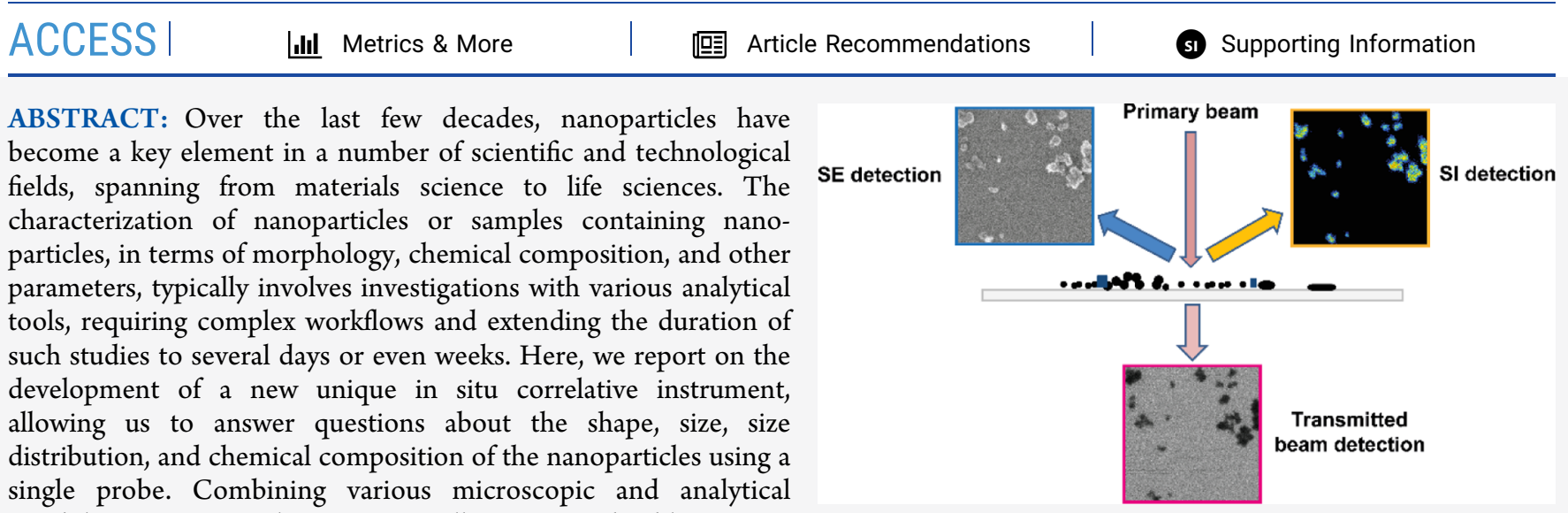
capabilities in one single instrument allows a considerable increase in flexibility and a reduction in the duration of such complex investigations. The new instrument is based on focused ion beam microscopy technology using a gas field ion source as a key enabler and combining it with specifically developed secondary ion mass spectrometry and scanning transmission ion microscopy technology. We will present the underlying concept, the instrument and its main components, and proof-of-concept studies performed on this novel instrument. For this purpose, different pure titanium dioxide nanoparticle samples were investigated. Furthermore, the distribution and localization of the nanoparticles in biological model systems were studied. Our results demonstrate the performance and usefulness of the instrument for nanoparticle investigations, paving the way for a number of future applications, in particular, nanotoxicological research.

\section{INTRODUCTION}

Nowadays, a vast number of scientific fields and related technologies involve nano-sized objects, structures, and materials. These can range from features in electronic devices, such as nanoscale grain boundary structures in solar cell materials, ${ }^{1}$ to effects of nanoparticles introduced into biological systems after environmental exposure or drug delivery. ${ }^{2}$ A vast number of different characterization techniques, including scanning electron microscopy (SEM) or transmission electron microscopy (TEM) and secondary ion (SI) mass spectrometry (SIMS) (to be further described below), have been used until now to study such samples in terms of their shape, size/size distribution, material composition, and their interaction/ relation with the surrounding matrix in order to assess the corresponding properties.

Nanoparticles are a particularly hot topic, as they are merging material and life science interests in research and society. Nowadays, they are used in a large number of consumer products such as children's goods (e.g., toys), clothing, cosmetics, paints, or even food, ${ }^{3}$ and therefore, we come in contact with them on a daily basis. The nanoparticles (nanomaterials) are used in the product to provide a specific function or enhance its performance (e.g., in sunscreen). However, they potentially represent risks in terms of health or more general environmental aspects. ${ }^{4,5}$ Nanomaterials can have toxic effects as they can negatively alter the properties of biological systems, for example, human cells or tissues, and therefore, a detailed investigation of possible effects is mandatory. Many different kinds of nanoparticles are used nowadays, ranging from metallic/metal oxide particles, for example, gold $(\mathrm{Au})$, silver $(\mathrm{Ag})$, titanium dioxide $\left(\mathrm{TiO}_{2}\right)$, and zinc oxide $(\mathrm{ZnO})$, to fullerenes $\left(\mathrm{C}_{60}\right)$ and single-/multi-wall carbon nanotubes to materials such as silicon dioxide $\left(\mathrm{SiO}_{2}\right)$, nanoclays, or organic matter such as nanocellulose. ${ }^{4,6,7}$

Received: June 3, 2021

Accepted: September 27, 2021

Published: October 20, 2021 
Imaging techniques such as SEM or TEM can be used to obtain laterally highly resolved topographic and structural information of the nano-sized objects and their surrounding environment (SEM: resolution of a few nanometers; TEM: below $0.1 \mathrm{~nm}$ resolution achievable). Chemical information on these instruments can be obtained by detecting specific signals emitted from the sample, resulting from its interaction with the scanning primary beam. Detection of X-rays in energydispersive X-ray spectroscopy (EDS) in TEM, for example, yields elemental information with nanometer or even atomic resolution. ${ }^{8,9}$ Nevertheless, EDS does not allow distinguishing between isotopes and has a detection limit of about $1000 \mathrm{ppm}$, which is insufficient for detecting trace elements. ${ }^{10,11}$ A more sensitive analytical technique is SIMS, ${ }^{12}$ which has the ability to detect isotopic information with far lower detection limits than EDS, namely, down to the ppm range. However, standalone commercial SIMS instruments are still currently limited to a lateral resolution of several tens of nanometers (i.e., sub-50 nm for the CAMECA NanoSIMS ${ }^{13,14}$ or the IONTOF $M 6^{15}$ ). An analytical technique that can compete with SIMS in terms of sensitivity is atom probe tomography (APT), offering a sub- $0.5 \mathrm{~nm}$ resolution. ${ }^{16,17}$ Nevertheless, due to complex sample preparation needs and significant limitations in the available field of view, the use of APT can be rather limiting.

A very promising nanoscale investigation tool, developed over the last 2 decades, is the helium ion microscope (HIM) based on gas field ion source (GFIS) technology. The GFIS provides very finely focused primary ion beams consisting of $\mathrm{He}^{+}$or $\mathrm{Ne}^{+}$ions to irradiate/scan sample surfaces with landing energies (energy of the primary ion hitting the sample) in the sub-35 keV range. The $\mathrm{He}^{+}$primary beam allows a $0.5 \mathrm{~nm}$ spatial resolution (probe size) when detecting secondary electrons $(\mathrm{SEs})^{18-20}\left(\mathrm{Ne}^{+}\right.$offers a $2 \mathrm{~nm}$ resolution, determined by edge resolution scans). The contrast in the recorded SE images is mainly related to topography and material-specific SE yields. ${ }^{21}$ Furthermore, the helium-induced SE imaging mode offers an excellent depth of field allowing highly structured surfaces to be imaged with high spatial resolution. ${ }^{21-23}$ In addition to SE imaging, the HIM can also be equipped with a specifically developed SIMS unit for analytical purposes. ${ }^{24-26}$ When the $\mathrm{He}^{+}$or $\mathrm{Ne}^{+}$primary ion beam impinges on the sample surface, the ions penetrate into the bulk of the material where they gradually lose their energy through collisions with sample atoms. The collision cascade leads to the sputtering of atoms or molecules from the sample surface. ${ }^{12,25} \mathrm{~A}$ fraction of those sputtered particles leaves the sample in an ionized state, the so-called SIs, which can be extracted with specific electrostatic optics before being transferred to the mass spectrometer for mass-filtered analysis. In this way, it is possible to perform SIMS analysis of surfaces with excellent detection sensitivity, a high dynamic range (signal variations over several orders of magnitude are detectable), and differentiating the various isotopes. ${ }^{27}$ It has been demonstrated that SIMS on the HIM can be performed with sub-20 nm lateral resolution, which gives outstanding results in that respect compared to standalone SIMS tools. ${ }^{24,26-29}$ The application fields covered by investigations using SIMS on the HIM range from thin-film studies, ${ }^{30}$ battery research, and optoelectronic devices characterization, ${ }^{25,31}$ to solar cell materials $^{32}$ or steel investigations, ${ }^{33}$ to geological and biological relevant topics. ${ }^{25,34,35}$ A most recent review summarizes the applications of HIM-SIMS. ${ }^{36}$
On the other hand, as the GFIS has the ability to create the light element $\mathrm{He}^{+}$beam, scanning transmission ion microscopy (STIM) can be explored on the HIM. The typical $30 \mathrm{keV} \mathrm{He}^{+}$ beam used in the HIM has a projected range spanning from tens to a few hundreds of nanometers in most materials (SRIM simulations). ${ }^{37}$ Therefore, for sufficiently thin samples (typically less than $100 \mathrm{~nm}$ ), a considerable fraction of the primary beam will pass through the sample and can be used as an imaging signal. The helium ions interact with both the electrons and nuclei of the atoms that make up the sample and undergo inelastic and elastic collisions along their way. These interactions depend on the material, its density, the local thickness, and the arrangement of the atoms in the sample. Consequently, the transmitted signal can provide contrasting information related to the mass-thickness product ${ }^{38-40}$ and some information on the crystalline structure of the sample. ${ }^{41-43}$ Additionally, the transmitted signal provides a way of localizing buried structures inside the sample that would not be possible to detect using surface-sensitive signals such as SE and SIMS without milling the area.

These GFIS imaging and analytics capabilities make it an ideal central enabler for a novel correlative tool to perform morphological, structural, and chemical characterization at the nanoscale by combining SE imaging, SIMS, and STIM techniques in one single instrument (Figure 1). Here, we therefore introduce the "npSCOPE" which combines these different techniques to perform in situ multi-modal studies in numerous scientific fields. npSCOPE stands for nanoparticle scope, as the tool is of utmost interest for nanoparticle-related research.

Traditionally, respective samples have to be transferred between different instruments (e.g., TEM for high-resolution imaging and SIMS for high-sensitivity chemical analysis). This approach is risky, costly, and especially time-consuming. By performing all relevant steps in the same instrument and on the same sample using the npSCOPE will significantly increase the flexibility and help in reducing the time and cost of the investigation campaigns.

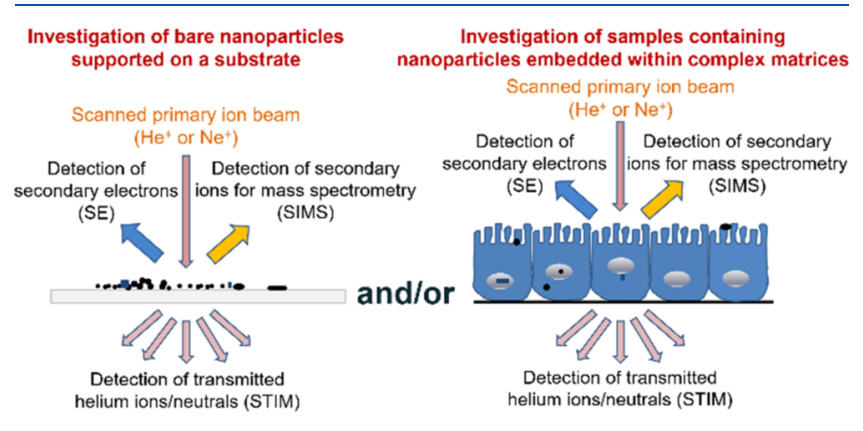

Figure 1. Illustration of the investigation approach for nanoparticle samples within the in situ multi-modal correlative instrument, npSCOPE.

\section{INSTRUMENT LAYOUT}

The complete assembled npSCOPE instrument is shown in Figure 2. The GFIS column is located on the vertical axis on top of the analysis chamber (UHV-compatible stainless steel vessel), which is equipped with a high-precision five-axis $(X, Y$, $Z$, rotation, and tilt) sample stage, standardly used in the HIM. In terms of detectors, the instrument comprises first a standard Everhart-Thornley detector located right above the sample to 


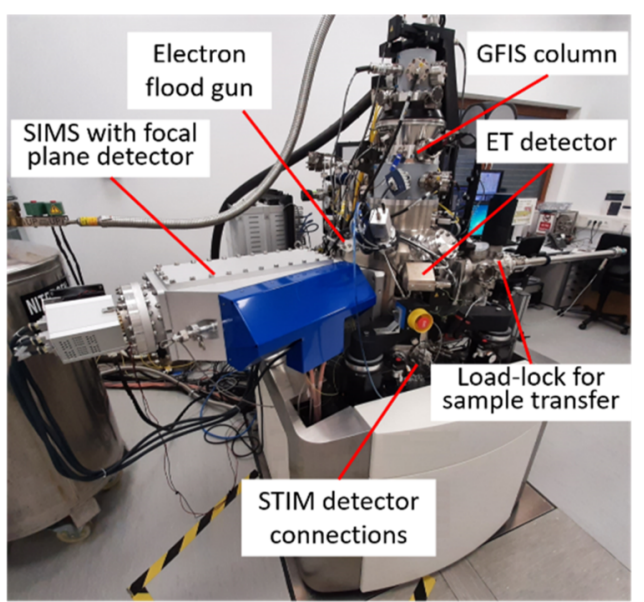

Figure 2. Photograph of the assembled npSCOPE instrument, combining the GFIS technology with different kinds of detectors for high-resolution imaging and analytics.

efficiently detect SEs. Second, a double-focusing magnetic sector SIMS system incorporating movable high-precision extraction and transfer optics as well as a novel mass-filtered detection concept is installed. Third, a newly developed twodimensional (2D) position-sensitive detector for STIM investigations is positioned below the sample stage onto a movable support structure. Moreover, the instrument is equipped with a low-energy electron flood gun for charge compensation when investigating insulating samples in the SE mode. This avoids the need for conductive coatings on the sample that might hide important nanoscale features.

SIMS Sub-system. The SIMS system used on the npSCOPE (Figure 3) is an advanced version of the SIMS

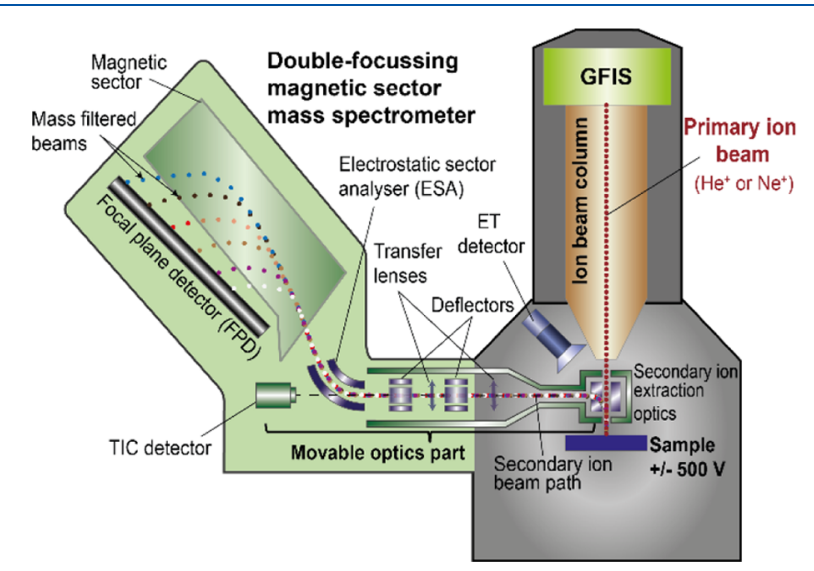

Figure 3. Schematic diagram of the compact double-focusing magnetic sector SIMS system on the npSCOPE, incorporating the newly developed continuous FPD. The plane of the SIMS is horizontal but was flipped to the vertical direction for illustration purposes.

add-on that we developed for the HIM and that was described elsewhere. ${ }^{25,44}$ In brief, it is based on novel SI extraction and transfer optics coupled with a compact double focusing magnetic sector mass spectrometer. The extraction optics can be precisely positioned between the end nozzle of the GFIS column and the sample by a piezo-driven positioner. These optics are designed in such a way to offer an efficient extraction of SIs while working at low potentials to have minimal influence on the primary ion beam passing through the optics. The transfer optics include a post-acceleration step to bring the SI beam to higher energies (a few keV) toward the detection part of the spectrometer. This results in the need of having an electrically floating setup for the complete SIMS system. The SIMS optics can be retracted for high lateral resolution imaging modes, for example, SE imaging at the shortest working distance.

In contrast to earlier versions of the SIMS used on a standard HIM, the SIMS system of npSCOPE incorporates a single continuous detector based on a microchannel plate (MCP) - delay line (DL) technology, ${ }^{45}$ along the focal plane of the magnetic sector instead of four individual channeltron detectors. This new focal plane detector (FPD) system allows parallel acquisition of the full mass spectrum for each scanned pixel across the sample surface, offering several key advantages over previous multi-collector detection systems, including (i) higher sensitivity by detecting the entire mass peaks, (ii) the acquisition of a full mass spectrum of the complete field of view in as little as $1 \mathrm{~s}$, and (iii) a multitude of post-processing techniques based on the generated SIMS hyperspectral data.

In addition to the FPD, the SIMS system also incorporates a total ion counter (TIC) detector placed after the transfer optics, allowing us to detect the non-mass-filtered SI signal in the positive mode and a combination of non-mass-filtered SI and SE signals in the negative mode. The TIC detector is most often used as a fast imaging detector offering complementary contrast information to the SE imaging mode.

The SIMS can be used in different modes: (1) acquisition of mass spectra, (2) mass-filtered images, (3) depth profiles (tracing selected signals while milling the sample), or (4) even three-dimensional (3D) chemical maps (stacking of several layers of mass-filtered images).

STIM Sub-system. The STIM detector is also based on MCP-DL technology. The 2D DL readout structure provides a position and time-sensitive detection capability for a complete investigation of the different contrast mechanisms available. Furthermore, the detector is mounted on to an in-vacuum vertical linear rail, allowing us to adjust the distance between the sample and the detector. This allows us to choose between recording high scattering angles or recording only the ions undergoing small-angle collisions and being scattered into lower scattering angles but at a higher angular resolution. The STIM experimental geometry is shown in Figure 4. Currently, the STIM sample is placed on a side-mounted extension arm with a hole underneath it. The stage has to be tilted at $45^{\circ}$ to align the sample and the hole with the axis of the primary beam in a construction similar to the one presented by another group. ${ }^{46}$

The STIM output is a $5 \mathrm{D}$ data set that combines the position of the beam on the sample $(x, y)$, with the position of the signal on the detector $(u, v)$ and a timestamp $(t)$ for each detected event. This information can be used in a postrecording analysis to form images based on either the beam that is transmitted at small angles [i.e., bright-field (BF) mode] or the deflected beam [i.e., dark-field (DF) mode] using a userdefined minimal cutoff polar angle. This later case is considered as the annular dark field mode and can yield a strong contrast for a selected mass-thickness combination, for example, a heavy element nanoparticle with a particular size in a light matrix. Moreover, by choosing certain angular ranges (regions) for both polar and azimuthal direction, it is possible to get STIM images related to specific scattering directions. 


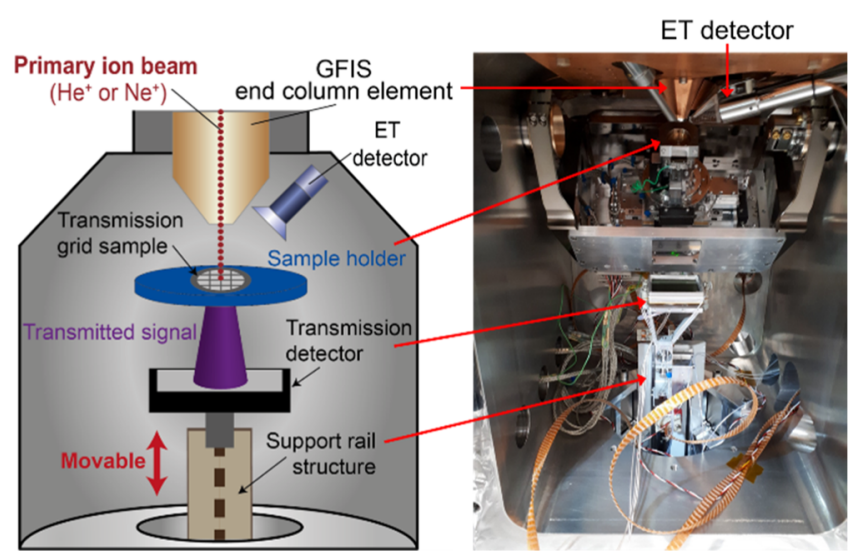

Figure 4. Left: Schematic representation of the STIM sub-system with the movable $2 \mathrm{D}$ position-sensitive transmission detector. Right: photograph of the interior of the npSCOPE instrument with the sample stage in a tilted position above the STIM sub-system.

Another way of working with the STIM setup is by placing the detector far away from the sample, and therefore, detecting only small-angle forward scattering. In this case, $\mathrm{BF}$ imaging is performed using the entire area of the detector. This allows for higher primary ion currents, hence faster imaging with a better signal-to-noise ratio at an improved angular resolution. Further complementary information about the STIM sub-system can be found in the work by Serralta et al. ${ }^{47}$

\section{EXPERIMENTAL SECTION}

Samples for Proof-of-Concept Testing: $\mathrm{TiO}_{2}$ Nanoparticles. Two different kinds of commercially available $\mathrm{TiO}_{2}$ nanoparticles were characterized and compared. The anatase sample [titanium (IV) oxide anatase, particles smaller than 25 nm, Sigma-Aldrich ${ }^{48}$ ] contains $100 \%$ of anatase $\mathrm{TiO}_{2}$, while the $\mathrm{E} 171 \mathrm{TiO}_{2}$ nanoparticle sample (size range: $20-440 \mathrm{~nm}^{49}$ ) contains not only anatase but also up to $5 \%$ of rutile $\mathrm{TiO}_{2}$. The $\mathrm{TiO}_{2}$ samples were used to perform proof-of-concept investigations with the npSCOPE. A small amount of both kinds of raw particles was dispersed with $1 \mathrm{ml}$ of pure ethanol. Clusters of particles were dissociated in an ultrasonic bath, and a volume of $2 \mu \mathrm{L}$ was drop-cast onto a Si wafer and onto a 300mesh copper grid with a lacey carbon support. After the evaporation of the alcohol, the samples were investigated in the npSCOPE instrument.

Daphnia magna Sample. D.magna were exposed following a modified OECD 202 guideline. ${ }^{50}$ Dormant eggs (ephippia; obtained from MicroBioTests Inc., Belgium) of $D$. magna were incubated in Petri dishes containing Volvic natural mineral water (Source Clairvic, Société des Eaux de Volvic, France) for 4 days at $21{ }^{\circ} \mathrm{C}$ under continuous light. Once hatched, the daphnids were fed with the green Desmodesmus subspicatus alga. Daphnids under $96 \mathrm{~h}$ old were exposed to 0, 1, and $10 \mu \mathrm{g} / \mathrm{mL} \mathrm{TiO}_{2}$ (anatase, $<25 \mathrm{~nm}$, Sigma) nanoparticles for $24 \mathrm{~h}$ in medium without algae. Afterward, the media with nanoparticles were removed and replaced with fresh Volvic mineral water media before processing the Daphnids with chemical fixation (2\% glutaraldehyde and 3\% formaldehyde in HEPES buffer) and EPON resin embedding according to standard procedures. Blocks were cut into $60 \mathrm{~nm}$-thick sections, and the sections were mounted onto Quantifoil copper grids with a carbon + formvar support film. The sections were post-stained using $2 \%$ uranyl acetate and lead citrate. The grids were imaged using a FEI Morgagni TEM operated at $100 \mathrm{kV}$ and using the npSCOPE.

\section{RESULTS AND DISCUSSION}

Pure $\mathrm{TiO}_{2}$ Nanoparticles-E171 and Anatase. The results obtained for both particle types using SE imaging (generated by a $30 \mathrm{keV} \mathrm{He}^{+}$beam) and SIMS (generated by a $25 \mathrm{keV} \mathrm{Ne}{ }^{+}$beam) are shown in Figures 5 and 6 . The images
1

FOV $10 \mu \mathrm{m}, 2.2 \mathrm{pA}$

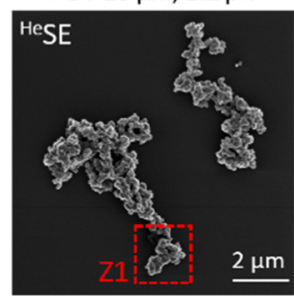

OV $10 \mu \mathrm{m}, 1.0 \mathrm{pA}$

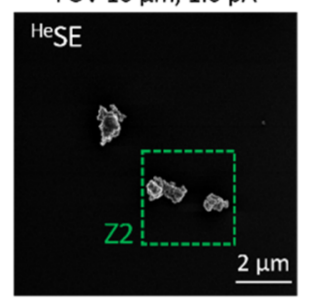

2

FOV $2 \mu \mathrm{m}, 1.0 \mathrm{pA}$

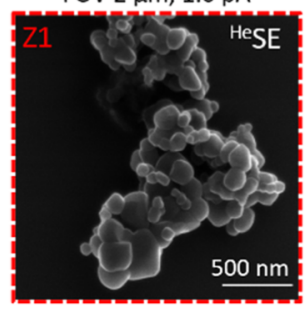

FOV $3 \mu \mathrm{m}, 1.0 \mathrm{pA}$

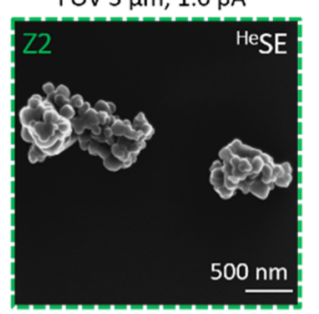

3

FOV $2 \mu \mathrm{m}, 2.0 \mathrm{pA}$

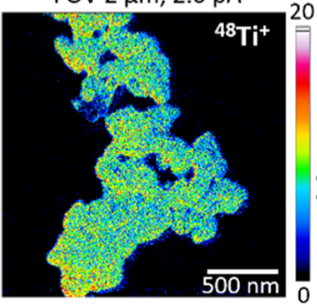

FOV $3 \mu \mathrm{m}, 1.0 \mathrm{pA}$

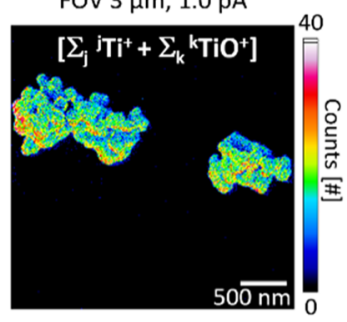

4
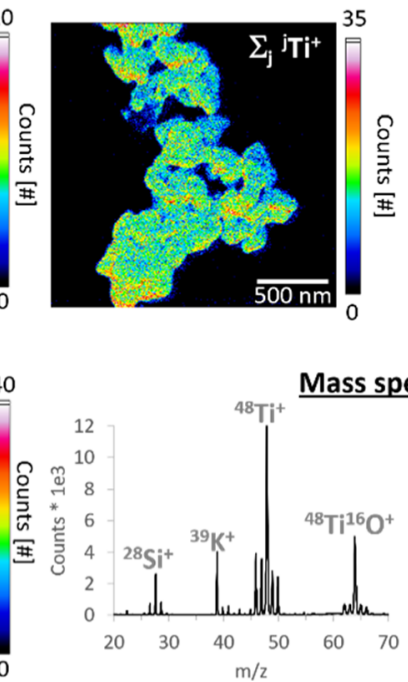

5

$\left[\Sigma_{\mathrm{j}} \mathrm{Ti}^{+}+\Sigma_{\mathrm{k}} \mathrm{kTiO}^{+}\right]$

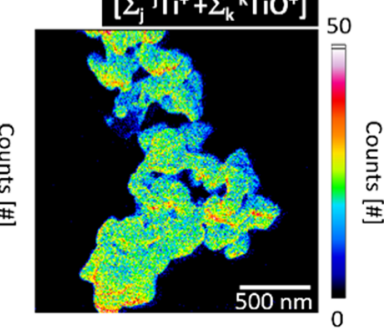

.

.


1

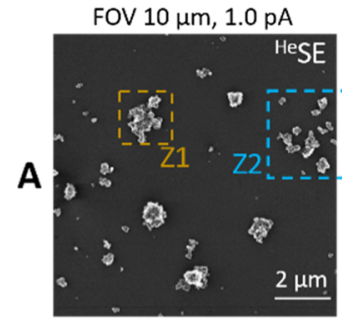

FOV $3 \mu \mathrm{m}, 0.4 \mathrm{pA}$

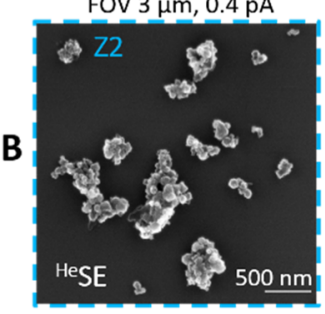

2
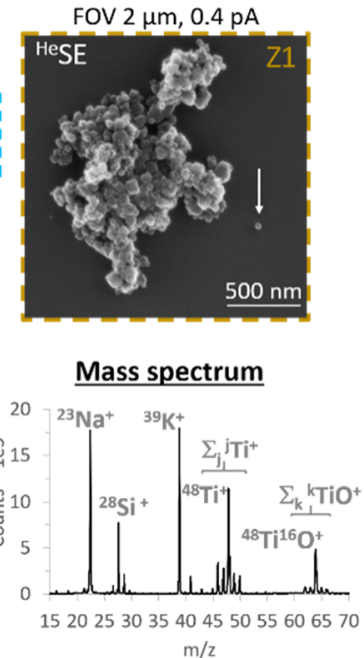

3

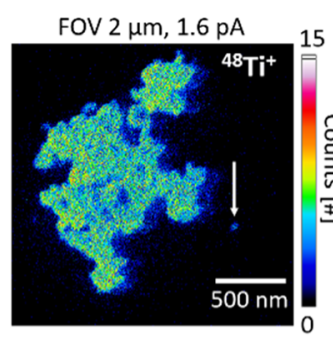

FOV $3 \mu \mathrm{m}, 1.6 \mathrm{pA}$

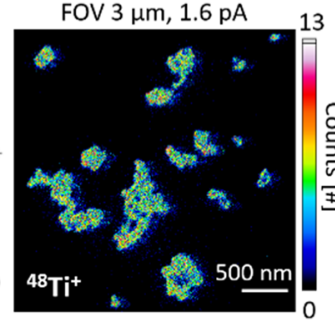

4 $\left[\Sigma_{j} \mathrm{TTi}^{+}+\Sigma_{k}{ }^{\mathrm{KTiO}^{+}}\right]$

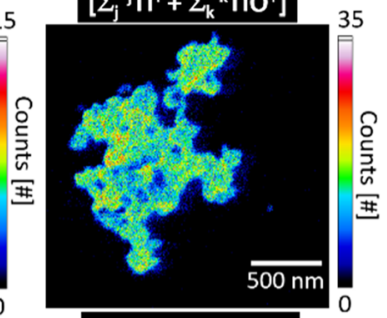

$\left[\Sigma_{\mathrm{i}} \mathrm{TT}^{+}+\Sigma_{\mathrm{k}}{ }^{\mathrm{k}} \mathrm{TiO}^{+}\right]$

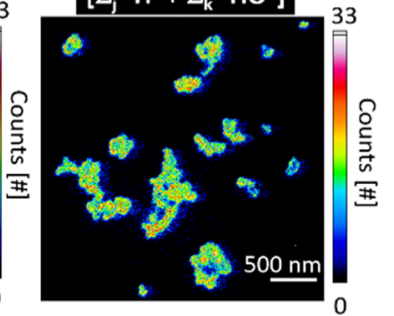

Figure 6. Exemplary SE images and corresponding SIMS analysis data of $\mathrm{TiO}_{2}$ anatase nanoparticles are presented. The SE images were taken at different FOV sizes (A1, A2, and B1), combined with the SIMS images representing different selected signals in the positive SI mode (A3, A4, B3, and B4). The corresponding mass spectrum is shown in image B2. The SIMS images A4 and B4 represent the signals obtained by summing up the peaks of all $\mathrm{Ti}$ isotopes and all $\mathrm{TiO}^{+}$cluster peaks. Note: It is hard to find single isolated nanoparticles (indicated by the white arrow in images $\mathrm{A} 2$ and A3), as particles tend to form agglomerations. ( ${ }^{\mathrm{He}} \mathrm{SE}$ mode: $\mathrm{He}^{+} 30 \mathrm{keV}$, dwell time $=5 \mu$ s; SIMS mode: $\mathrm{Ne}^{+} 25 \mathrm{keV}$, dwell time $=1 \mathrm{~ms}$ ).
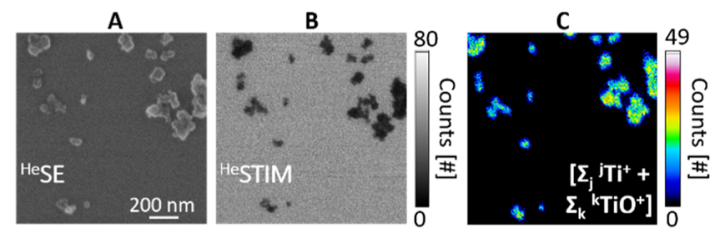

Figure 7. Corresponding SE (A), total counts STIM (B) (max. collection angle $=7.8^{\circ}$ ), and SIMS $(\mathrm{C})$ images of $\mathrm{TiO}_{2}$ anatase nanoparticles. Note that in small FOVs (here $1.5 \mu \mathrm{m}$ ), a slight shift in image orientation between SE/STIM and SIMS images can occur. The SE and STIM images were taken at the same working distance (at about $25 \mathrm{~mm}$ ). Dwell times: SE $1 \mu \mathrm{s}$ at $I_{\mathrm{He}}=1.5 \mathrm{pA}$, total counts: STIM $110 \mu \mathrm{s}$ at $I_{\mathrm{He}}=1.5 \mathrm{pA}$ and SIMS $2000 \mu \mathrm{s}$ at $I_{\mathrm{Ne}}=1.6 \mathrm{pA}$.

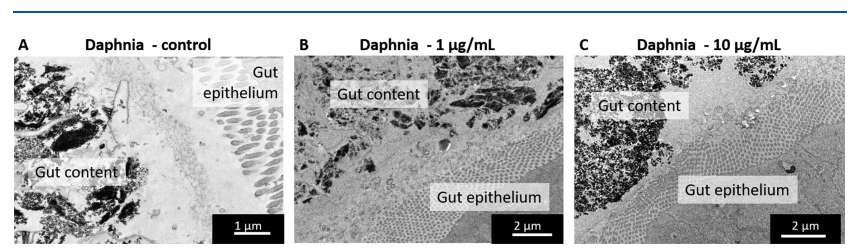

Figure 8. TEM analysis of D. magna tissue sections. (A) D. magna control sample (no $\mathrm{TiO}_{2}$ nanoparticles), (B) D. magna fed with $1 \mu \mathrm{g}$ / $\mathrm{mL}$ of $\mathrm{TiO}_{2}$ nanoparticles suspended in medium, and (C) D. magna fed with $10 \mu \mathrm{g} / \mathrm{mL}$ of $\mathrm{TiO}_{2}$ nanoparticles; Villi of the gut epithelium and gut content can be observed. In particular, the sample fed with 10 $\mathrm{mg} / \mathrm{mL}$ of $\mathrm{TiO}_{2}$ nanoparticles (C) contains high amounts of electrondense small particles within the gut lumen.

indicate agglomeration. Nevertheless, due to the high lateral resolution capability of the $\mathrm{He}^{+} \mathrm{SE}$ imaging mode, the high depth of field, and especially the high topographic contrast, it is possible to identify individual nanoparticles in these agglomerations. Such SE images can be used for nanoparticle size and size distribution determinations as illustrated in the Supporting Information (Figure S1).

For both nanoparticle samples, the obtained mass spectra are shown in Figures 5 (B4, B5) and 6 (B2). The spectra show the typical distribution of the $\mathrm{Ti}$ isotopes and the
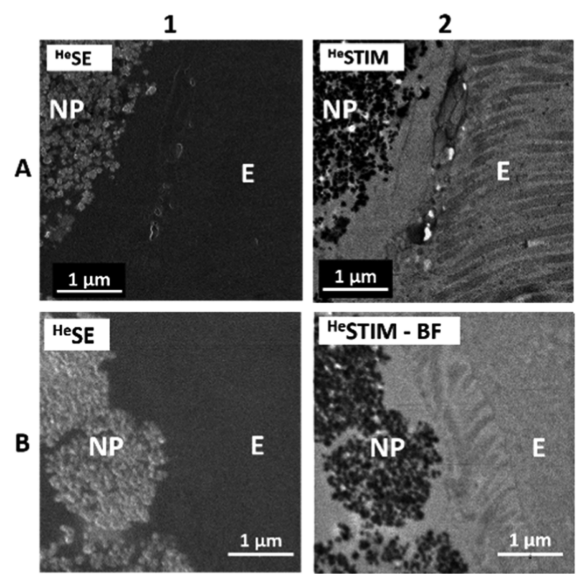

3
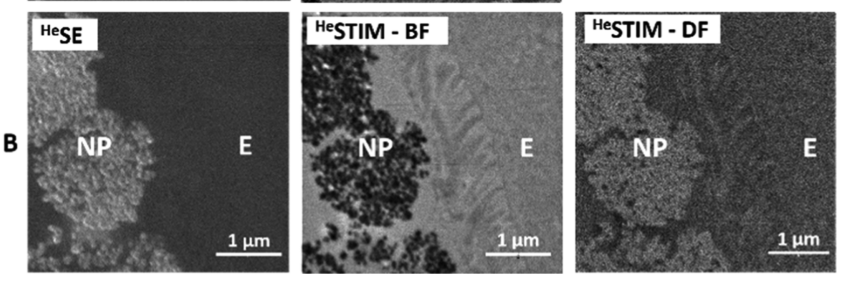

Figure 9. SE and STIM imaging of D. magna tissue sections. Row A: Osmiophilic cellular structures such as the villi of the gut epithelium (E), as well as the high mass thickness product $\mathrm{TiO}_{2}$ nanoparticles are clearly visible with total count STIM imaging (maximum collection angle of $7.8^{\circ}$ ). Row B: SE imaging and the corresponding STIM images in the BF mode (collection angle: $0^{\circ}$ to $4^{\circ}$ ), and in the annular DF mode (collection angle: $10.3^{\circ}$ to $13.9^{\circ}$ ).

corresponding $\mathrm{TiO}$ peaks. In order to obtain SIMS images of the nanoparticles and correlate them with the highly resolved SE images, the ${ }^{48} \mathrm{Ti}^{+}$signal can be used as shown in the corresponding SIMS images of Figure 5 (A3) and Figure 6 (A3, B3). Previous SIMS generations using four filtering-slit detectors (e.g., channeltrons) only allow the detection of a fraction of the intensity for a selected mass. In contrast, the SIMS equipped with the continuous FPD allows the detection of the full mass peak, as well as the simultaneous detection of all isotopes of a given element and all clusters containing these isotopes. The signals of these isotopes and related cluster ions can then be summed up. This is an important benefit leading to a significant signal increase, which enhances the sensitivity and the signal-to-noise ratio of the images. This is illustrated, for example, in Figure 5 when comparing the ${ }^{48} \mathrm{Ti}^{+}$(A3) to the 

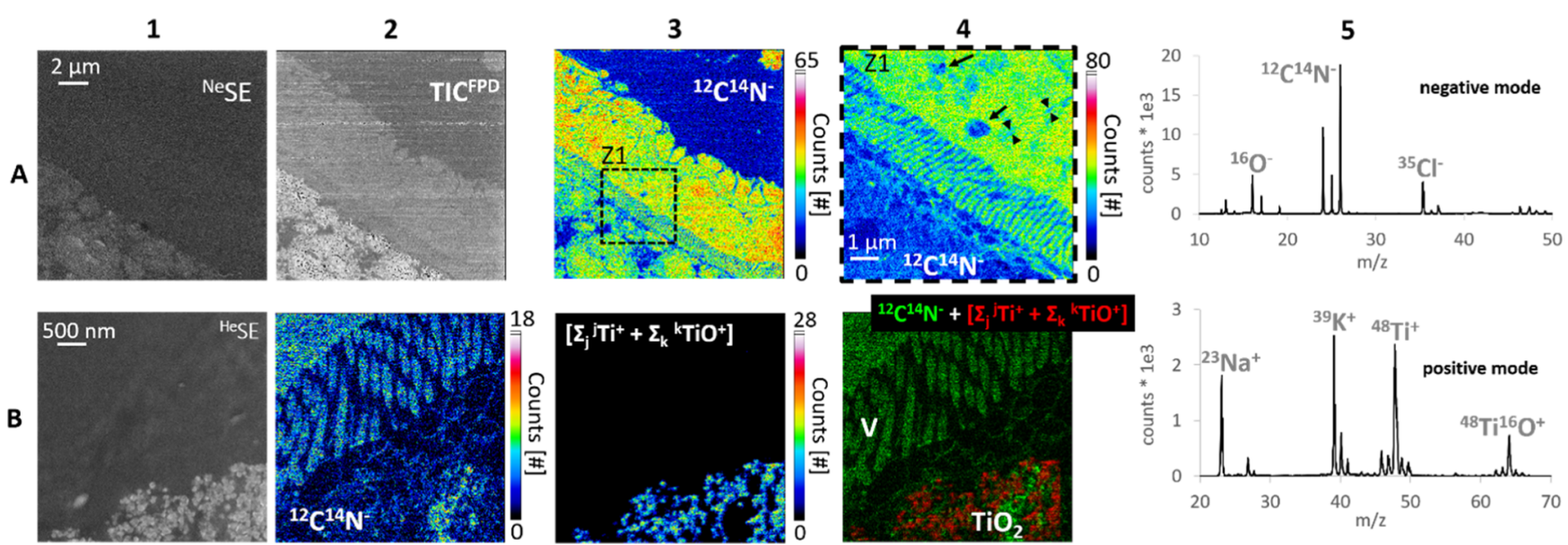

Figure 10. SE, TIC, and SIMS images of D. magna exposed to $10 \mu \mathrm{g} / \mathrm{mL} \mathrm{TiO}_{2}$ anatase. While SE images (A1 and B1) of flat sections only reveal the $\mathrm{TiO}_{2}$ nanoparticles, negative polarity TIC images (A2) as well as ${ }^{12} \mathrm{C}^{14} \mathrm{~N}^{-}$SI images can also show biological structures (A3, A4, and B2). The boxed area (in A3) was re-analyzed with SIMS using a smaller field of view of $8 \mu \mathrm{m}$ (A4). The arrows highlight structures that can correspond to subcellular compartments, probably vesicles and cell borders (between arrow heads), respectively. High-resolution SIMS using the negative (B2) and positive (B3) SI mode on the same area of interest, allowing the superposition of ${ }^{12} \mathrm{C}^{14} \mathrm{~N}^{-}$and $\left[\Sigma_{\mathrm{j}}{ }^{\mathrm{j}} \mathrm{Ti}^{+}+\Sigma_{\mathrm{k}}{ }^{\mathrm{k}} \mathrm{TiO}{ }^{+}\right]$signals $(\mathrm{B} 4)$. The corresponding mass spectra are shown in A5 and B5. (Row A: $\mathrm{Ne}^{+} 20 \mathrm{keV} / 5.5 \mathrm{pA}, \mathrm{SE} / \mathrm{SIMS}$ dwell time $=1 \mu \mathrm{s} / 8 \mathrm{~ms}$; Row B: SE: He ${ }^{+} 25 \mathrm{keV} / 2$ $\mathrm{pA}$, dwell time $=1 \mu \mathrm{s}$; SIMS: $\mathrm{Ne}^{+} 25 \mathrm{keV} / 2 \mathrm{pA}$, dwell time $=1 \mathrm{~ms}$ pos. mode $/ 8 \mathrm{~ms}$ neg. mode; $\mathrm{V}$ : villi of the epithelium).

$\left[\Sigma_{\mathrm{j}}{ }^{\mathrm{j}} \mathrm{Ti}^{+}\right](\mathrm{A} 4)$ and the $\left[\Sigma_{\mathrm{j}}{ }^{\mathrm{j}} \mathrm{Ti}^{+}+\Sigma_{\mathrm{k}}{ }^{\mathrm{k}} \mathrm{TiO}^{+}\right]$(A5) SIMS images. Here, a signal increase by a factor of $2-3$ is observed compared to the ${ }^{48} \mathrm{Ti}^{+}$image. To optimize the signal intensity, the SIMS aperture was fully retracted, leading to a lower mass resolution $\left[\mathrm{m} / \Delta m\left(\Delta m\right.\right.$ taken as fwhm) around 150 on the ${ }^{48} \mathrm{Ti}^{+}$peak compared to 500 when inserting an aperture].

What can further be seen, for example, in the SIMS image B3 of Figure 5 is that the SIMS mode is able to resolve even the individual smaller particles of the agglomeration represented for the E171 sample. The intensity line scans across particle edges reveal an edge resolution of $12 \mathrm{~nm}$ (using a $75-25 \%$ intensity variation definition). The SE images obtained at the same working distance as for SIMS $(18 \mathrm{~mm}$, Figures 5 and 6) show an edge resolution of about $4 \mathrm{~nm}$. Note that the nanometer to sub-nanometer resolution is possible in the SE imaging mode when using smaller working distances. In this correlative SE-SIMS setup, the workflow most often consists of first taking the SE images with a He beam and then switching to the SIMS mode with a $\mathrm{Ne}$ beam to obtain the corresponding analytical data. The switch between both imaging modes takes up to $15 \mathrm{~min}$ and involves the change from $\mathrm{He}$ to $\mathrm{Ne}$ gas, a fine-tuning of the GFIS column and SIMS system and a precise adjustment of the imaged region of interest (ROI) for correlative purposes.

The current instrument setup requires the use of different sample holders and stage orientations if SE, STIM, and SIMS analyses are to be performed on the same ROI. This process is tedious and challenging as the grid must be moved between the different sample holders. This workflow is however still feasible, as illustrated in Figure 7. The current STIM setup limits the working distance to about $25 \mathrm{~mm}$, which negatively affects the lateral resolution achievable in the STIM mode. For example, the lateral resolution determined through line scans across nanoparticle edges in Figure $7 \mathrm{~B}$ amounts to about $6 \mathrm{~nm}$. At working distances below $8 \mathrm{~mm}$, we expect a lateral resolution in the STIM mode comparable to what can be achieved in the SE mode, namely, about $1 \mathrm{~nm}$. Stage modifications that are currently being implemented will allow us to carry out all three imaging modalities at their respective optimal working distance while using the same sample holder. This will greatly streamline correlative investigations.

D. magna Sample. The D. magna sections were first investigated by TEM (Figure 8), confirming the presence of small electron-dense particles, probably $\mathrm{TiO}_{2}$, in the gut. However, since small electron-dense material also accumulates in the gut when no $\mathrm{TiO}_{2}$ is fed, a confirmation of $\mathrm{TiO}_{2}$ nanoparticle localization and possible transport into the gut epithelium needs to be obtained by chemical analysis (SIMS). Using the npSCOPE, STIM analysis (Figure 9 A2, B2, and B3) is able to show details such as cellular borders or villi, which highly simplify the orientation in the flat resin sections. Contrarily, SE imaging on the flat sections shows only the contrast of the $\mathrm{TiO}_{2}$ nanoparticles; biological information is not retrieved due to low SE contrast between the resin and the biological structures (Figure $9 \mathrm{~A} 1$ and B1). Complementary to STIM, biological information can also be obtained using the SIMS sub-system in the TIC imaging mode in the negative polarity (TIC detector or total integrated signal on the FPD, see Figure $10 \mathrm{~A} 2$ for an example). In the negative mode, the $m / z 26$ peak corresponds to the ${ }^{12} \mathrm{C}^{14} \mathrm{~N}^{-}$signal characteristic for cellular structures (see mass spectra of Figure 10 A5). Note that the content of vesicles present in the cytoplasm is visible as empty spaces in the ${ }^{12} \mathrm{C}^{14} \mathrm{~N}^{-}$signal image, yielding additional biological contrast (arrows in Figure 10 A4). Subcellular structures, such as cell borders and microvilli are also visible in the $\mathrm{CN}^{-}$maps. The SIMS data clearly shows the localization of the $\mathrm{TiO}_{2}$ nanoparticles in the gut lumen; transport beyond the epithelial barrier was not observed (Figure 10 B2, B3), suggesting that the NPs might be trapped by luminal debris already present in the gut or that $24 \mathrm{~h}$ exposure time is not long enough for $\mathrm{TiO}_{2} \mathrm{NPs}$ to be internalized. This pattern of retention with the absence of internalization has also been described where daphnids were exposed to other NPs (e.g., for $\mathrm{CuO},{ }^{51} \mathrm{CNTs}^{52}$ or $20 \mathrm{~nm} \mathrm{Au}$ $\mathrm{NPs}^{53}$ ). It cannot be excluded that such retained NPs also block proper digestion and absorption of food particles. In contrast, CdS/ZnS quantum dots that were surface modified with uncharged polyethylene glycol, positively charged amino- 
terminated, and negatively charged carboxyl groups were taken up and crossed the D. magna intestinal barrier. ${ }^{54}$

\section{CONCLUSIONS}

The npSCOPE is a new multi-modal tool equipped with a GFIS primary ion column to generate and correlate high lateral resolution SE imaging, STIM, and SIMS data. This opens new innovative ways of performing physico-chemical studies on nanoparticle samples. The investigation of pure nanoparticle samples has demonstrated the instrument's performance in terms of highly resolved imaging to examine the morphology of the nanoparticles. For instance, these data sets allow us to determine the sizes and size distributions of nanoparticles. The SIMS mode provides detailed information about the composition of individual nanoparticles and hence complements the SE imaging data. For biological samples containing nanoparticles, the STIM mode proved its benefit by offering enhanced contrast in such flat section samples compared to the SE imaging mode and therefore allowed a better navigation and localization of regions of interest in such samples. The contrast in the STIM images is comparable to what is known from TEM investigations of identical sample systems. Moreover, by complementing these results with SIMS data, it is possible to clearly identify the localized nanosized objects by determining their chemical composition. Using these characteristics, the npSCOPE instrument can become a useful tool in the field of nanotoxicology. In this context, the instrument will be equipped with cryo-capabilities to investigate the biological samples close to their native state.

\section{ASSOCIATED CONTENT}

\section{SI Supporting Information}

The Supporting Information is available free of charge at https://pubs.acs.org/doi/10.1021/acs.analchem.1c02337.

Nanoparticle size and size distribution measurement using SE images (PDF)

\section{AUTHOR INFORMATION}

\section{Corresponding Author}

Olivier De Castro - Advanced Instrumentation for NanoAnalytics (AINA), MRT Department, Luxembourg Institute of Science and Technology, L-4422 Belvaux, Luxembourg; (1) orcid.org/0000-0001-9968-6695;

Email: olivier.decastro@list.lu

\section{Authors}

Antje Biesemeier - Advanced Instrumentation for NanoAnalytics (AINA), MRT Department, Luxembourg Institute of Science and Technology, L-4422 Belvaux, Luxembourg

Eduardo Serralta - Institute of Ion Beam Physics and Materials Research, Helmholtz-Zentrum Dresden-Rossendorf e.V., 01328 Dresden, Germany

Olivier Bouton - Prototyping, MRT Department, Luxembourg Institute of Science and Technology, L-4422 Belvaux, Luxembourg

Rachid Barrahma - Prototyping, MRT Department, Luxembourg Institute of Science and Technology, L-4422 Belvaux, Luxembourg

Quang H. Hoang - Advanced Instrumentation for NanoAnalytics (AINA), MRT Department, Luxembourg Institute of Science and Technology, L-4422 Belvaux, Luxembourg
Sebastien Cambier - Environmental Health, ERIN Department, Luxembourg Institute of Science and Technology, L-4422 Belvaux, Luxembourg

Tatjana Taubitz - Advanced Instrumentation for NanoAnalytics (AINA), MRT Department, Luxembourg Institute of Science and Technology, L-4422 Belvaux, Luxembourg

Nico Klingner - Institute of Ion Beam Physics and Materials Research, Helmholtz-Zentrum Dresden-Rossendorf e.V., 01328 Dresden, Germany; 이이.org/0000-0001-95395874

Gregor Hlawacek - Institute of Ion Beam Physics and Materials Research, Helmholtz-Zentrum Dresden-Rossendorf e.V., 01328 Dresden, Germany; ㅇo이.org/0000-00017192-716X

Serge Duarte Pinto - Photonis Netherlands B.V., 9301 ZR Roden, The Netherlands

Peter Gnauck - Carl Zeiss Microscopy GmbH, ZEISS Group, D-73447 Oberkochen, Germany

Falk Lucas - ETH Zurich, ScopeM, 8093 Zurich, Switzerland

Cecilia Bebeacua - ETH Zurich, ScopeM, 8093 Zurich, Switzerland

Tom Wirtz - Advanced Instrumentation for Nano-Analytics (AINA), MRT Department, Luxembourg Institute of Science and Technology, L-4422 Belvaux, Luxembourg

Complete contact information is available at:

https://pubs.acs.org/10.1021/acs.analchem.1c02337

\section{Notes}

The authors declare no competing financial interest.

\section{ACKNOWLEDGMENTS}

This work has received funding from the European Union's Horizon 2020 Research and Innovation Programme under grant agreement no. 720964 and was supported by the Luxembourg National Research Fund via the project INTER/ DFG/19/13992454.

\section{REFERENCES}

(1) Schöppe, P.; Schönherr, S.; Wuerz, R.; Wisniewski, W.; Martínez-Criado, G.; Ritzer, M.; Ritter, K.; Ronning, C.; Schnohr, C. S. Nano Energy 2017, 42, 307-313.

(2) Tureli, N.; Tureli, A. E.; Schneider, M. Drug Deliv. Lett. 2014, 4, 193-207.

(3) Vance, M. E.; Kuiken, T.; Vejerano, E. P.; McGinnis, S. P.; Hochella, M. F.; Rejeski, D.; Hull, M. S. Beilstein J. Nanotechnol. 2015, 6, 1769-1780.

(4) OECD. Env/Jm/Mono(2014)15 Meeting of the Chemicals Committee and the Working Party on Chemicals, Pesticides and Biotechnology Report of the Oecd Expert Meeting on the Physical Chemical Properties of Manufactured Nanomaterials and Test Guidelines; OECD, 2014.

(5) Rasmussen, K.; Rauscher, H.; Kearns, P.; González, M.; Riego Sintes, J. Regul. Toxicol. Pharmacol. 2019, 104, 74-83.

(6) OECD. Testing Programme of Manufactured Nanomaterials Overview. https://www.oecd.org/chemicalsafety/nanosafety/ overview-testing-programme-manufactured-nanomaterials.htm (accessed Oct 1, 2020).

(7) Miller, J. Nanocellulose Challenges and Opportunities: End User Perspectives; TAPPI, 2018.

(8) Titus, M. S.; Suzuki, A.; Mills, M. J.; Pollock, T. M. Microsc. Microanal. 2014, 20, 1028-1029.

(9) Daniel, R.; Houston, D.; Salmon, M. Atomic Resolution EDS. https://www.eag.com/resources/appnotes/atomic-resolution-eds/ (accessed Jun 1, 2021). 
(10) Goldstein, J. I.; Newbury, D. E.; Michael, J. R.; Ritchie, N. W. M.; Scott, J. H. J.; Joy, D. C. Scanning Electron Microscopy and X-Ray Microanalysis; Springer: New York, NY, 2018.

(11) Williams, D. B.; Carter, C. B. Transmission Electron Microscopy; Springer: US: Boston, MA, 2009.

(12) Benninghoven, A.; Rudenauer, F. G.; Werner, H. W. Secondary Ion Mass Spectrometry: Basic Concepts, Instrumental Aspects, Applications and Trends; Wiley-Interscience: New York, 1987.

(13) Hoppe, P.; Cohen, S.; Meibom, A. Geostand. Geoanal. Res. 2013, 37, 111-154.

(14) Li, K.; Liu, J.; Grovenor, C. R. M.; Moore, K. L. NanoSIMS Imaging and Analysis in Materials Science. Annual Review of Analytical Chemistry; Annual Reviews Inc., 2020; Vol. 13, pp 273-292.

(15) Kollmer, F.; Paul, W.; Krehl, M.; Niehuis, E. Surf. Interface Anal. 2013, 45, 312-314.

(16) CAMECA. Introduction to APT. https://www.cameca.com/ products/apt/technique (accessed Apr 29, 2021).

(17) Gault, B.; Moody, M. P.; De Geuser, F.; La Fontaine, A.; Stephenson, L. T.; Haley, D.; Ringer, S. P. Microsc. Microanal. 2010, $16,99-110$

(18) Morgan, J.; Notte, J.; Hill, R.; Ward, B. Micros. Today 2006, 14, 24-31.

(19) Rahman, F. H. M.; McVey, S.; Farkas, L.; Notte, J. A.; Tan, S.; Livengood, R. H. Scanning 2012, 34, 129-134.

(20) Notte, J.; Huang, J.; Urban, R.; Wolkow, R. A.; Pitters, J. L.; Lehtinen, O.; Kotakoski, J.; Timilsina, R.; Rack, P. D.; Petrov, Y. V.; Vyvenko, O. F.; Boden, S. A.; Gölzhäuser, A.; Hlawacek, G.; Vieker, H.; Beyer, A.; Veligura, G. V.; van Gasteland, R.; Poelsema, B.; Zhou, Y.; Fox, D. S.; Zhang, H.; Heller, R.; Klingner, N.; Wirtz, T.; Dowsett, D.; Philipp, P.; Shorubalko, I.; Pillatsch, L.; Utke, I.; Kalhor, N.; Alkemade, P. F. A.; Cybart, S. A.; Bali, R.; Röder, F.; Fassbender, J.; Zahid, O. K.; Hall, A. R.; Tan, S.; Livengood, R.; Ward, B. Helium Ion Microscopy; Hlawacek, G., Gölzhäuser, A., Eds.; Springer International Publishing Switzerland, 2016; Vol. 1.

(21) Petrov, Y. V.; Vyvenko, O. F. Helium Ion Microscopy; Hlawacek, G., Gölzhäuser, A., Eds.; Springer Nature: Basel, Switzerland, 2016; pp 119-146.

(22) Scipioni, L.; Sanford, C. A.; Notte, J.; Thompson, B.; McVey, S. J. Vac. Sci. Technol. B 2009, 27, 3250-3255.

(23) Boden, S. A. Introduction to Imaging Techniques in the HIM. Helium Ion Microscopy; Hlawacek, G., Gölzhäuser, A., Eds.; Springer Nature: Basel, Switzerland, 2016; pp 149-172.

(24) Wirtz, T.; Dowsett, D.; Philipp, P. SIMS on the Helium Ion Microscope: A Powerful Tool for High-Resolution High-Sensitivity Nano-Analytics. In Helium Ion Microscopy; Hlawacek, G., Golzhäuser, A., Eds.; Springer Berlin/Heidelberg, 2016; pp 297-323.

(25) Wirtz, T.; De Castro, O.; Audinot, J.-N.; Philipp, P. Annu. Rev. Anal. Chem. 2019, 12, 523-543.

(26) Klingner, N.; Heller, R.; Hlawacek, G.; Facsko, S.; von Borany, J. Ultramicroscopy 2019, 198, 10-17.

(27) Wirtz, T.; Vanhove, N.; Pillatsch, L.; Dowsett, D.; Sijbrandij, S.; Notte, J. Appl. Phys. Lett. 2012, 101, 1-5.

(28) Pillatsch, L.; Vanhove, N.; Dowsett, D.; Sijbrandij, S.; Notte, J.; Wirtz, T. Appl. Surf. Sci. 2013, 282, 908-913.

(29) Klingner, N.; Heller, R.; Hlawacek, G.; Borany, J. v.; Notte, J.; Facsko, S. Ultramicroscopy 2016, 162, 91-97.

(30) Lunca-Popa, P.; Botsoa, J.; Bahri, M.; Crêpellière, J.; Desgardin, P.; Audinot, J.-N.; Wirtz, T.; Arl, D.; Ersen, O.; Barthe, M.-F.; Lenoble, D. Sci. Rep. 2020, 10, 1-9.

(31) Wheatcroft, L.; Klingner, N.; Heller, R.; Hlawacek, G.; Özkaya, D.; Cookson, J.; Inkson, B. J. ACS Appl. Energy Mater. 2020, 3, 88228832.

(32) Gratia, P.; Zimmermann, I.; Schouwink, P.; Yum, J.-H.; Audinot, J.-N.; Sivula, K.; Wirtz, T.; Nazeeruddin, M. K. ACS Energy Lett. 2017, 2, 2686-2693.

(33) Gaderbauer, W.; Arndt, M.; Truglas, T.; Steck, T.; Klingner, N.; Stifter, D.; Faderl, J.; Groiss, H. Surf. Coating. Technol. 2020, 404, 126466.
(34) Fizesan, I.; Cambier, S.; Moschini, E.; Chary, A.; Nelissen, I.; Ziebel, J.; Audinot, J.-N.; Wirtz, T.; Kruszewski, M.; Pop, A.; Kiss, B.; Serchi, T.; Loghin, F.; Gutleb, A. C. Part. Fibre Toxicol. 2019, 16, 14.

(35) Gillois, K.; Stoffels, C.; Leveque, M.; Fourquaux, I.; Blesson, J.; Mils, V.; Cambier, S.; Vignard, J.; Terrisse, H.; Mirey, G.; Audinot, J.N.; Theodorou, V.; Ropers, M.-H.; Robert, H.; Mercier-Bonin, M. Sci. Total Environ. 2021, 754, 142324.

(36) Audinot, J.-N.; Philipp, P.; De Castro, O.; Biesemeier, A.; Hoang, Q. H.; Wirtz, T. Rep. Prog. Phys. 2021, 84, 105901-41.

(37) Ziegler, J. F.; Ziegler, M. D.; Biersack, J. P. Nucl. Instrum. Methods Phys. Res. Sect. B Beam Interact. Mater. Atoms 2010, 268, $1818-1823$

(38) Scipioni, L.; Ferranti, D. C.; Smentkowski, V. S.; Potyrailo, R. A. J. Vac. Sci. Technol., B: Nanotechnol. Microelectron.: Mater., Process., Meas., Phenom. 2010, 28, C6P18-C6P23.

(39) Hall, A. R. Microsc. Microanal. 2013, 19, 740-744.

(40) Woehl, T. J.; White, R. M.; Keller, R. R. Microsc. Microanal. 2016, 22, 544-550.

(41) Iv, J. N.; Hill, R.; McVey, S. M.; Ramachandra, R.; Griffin, B.; Joy, D. Microsc. Microanal. 2010, 16, 599-603.

(42) Allen, L. J.; D’Alfonso, A. J. Microsc. Microanal. 2012, 18, 698699

(43) Wang, J.; Huang, S. H. Y.; Herrmann, C.; Scott, S. A.; Schiettekatte, F.; Kavanagh, K. L. J. Vac. Sci. Technol. B 2018, 36, 021203.

(44) Dowsett, D.; Wirtz, T. Anal. Chem. 2017, 89, 8957-8965.

(45) Wirtz, T.; De Castro, O.; Biesemeier, A.; Hoang, H. Q.; Audinot, J.-N. Microsc. Microanal. 2020, 26, 1972-1974.

(46) Kavanagh, K. L.; Herrmann, C.; Notte, J. A. J. Vac. Sci. Technol. B 2017, 35, 06G902.

(47) Serralta, E.; Klingner, N.; De Castro, O.; Mousley, M.; Eswara, S.; Duarte Pinto, S.; Wirtz, T.; Hlawacek, G. Beilstein J. Nanotechnol. 2020, 11, 1854-1864.

(48) Sigma Aldrich. Product Specification-TiO2 Anatase-637254, 2021; p 1.

(49) Guillard, A.; Gaultier, E.; Cartier, C.; Devoille, L.; Noireaux, J.; Chevalier, L.; Morin, M.; Grandin, F.; Lacroix, M. Z.; Coméra, C.; Cazanave, A.; de Place, A.; Gayrard, V.; Bach, V.; Chardon, K.; Bekhti, N.; Adel-Patient, K.; Vayssière, C.; Fisicaro, P.; Feltin, N.; de la Farge, F.; Picard-Hagen, N.; Lamas, B.; Houdeau, E. Part. Fibre Toxicol. 2020, 17, 51 .

(50) Georgantzopoulou, A.; Balachandran, Y. L.; Rosenkranz, P.; Dusinska, M.; Lankoff, A.; Wojewodzka, M.; Kruszewski, M.; Guignard, C.; Audinot, J.-N.; Girija, S.; Hoffmann, L.; Gutleb, A. C. Nanotoxicology 2012, 7, 1168-1178.

(51) Heinlaan, M.; Kahru, A.; Kasemets, K.; Arbeille, B.; Prensier, G.; Dubourguier, H.-C. Water Res. 2011, 45, 179-190.

(52) Petersen, E. J.; Akkanen, J.; Kukkonen, J. V. K.; Weber, W. J. Environ. Sci. Technol. 2009, 43, 2969-2975.

(53) Khan, F. R.; Kennaway, G. M.; Croteau, M.-N.; Dybowska, A.; Smith, B. D.; Nogueira, A. J. A.; Rainbow, P. S.; Luoma, S. N.; Valsami-Jones, E. Chemosphere 2014, 100, 97-104.

(54) Feswick, A.; Griffitt, R. J.; Siebein, K.; Barber, D. S. Aquat. Toxicol. 2013, 130-131, 210-218. 